\title{
CLINICAL AND HAEMATOLOGICAL PROFILE IN MALARIA AT A TERTIARY CARE HOSPITAL
}

\author{
Chaya Ashok Kumar1, Dipti Gaikwad², Sujata Baveja ${ }^{3}$
}

${ }_{1}^{1}$ Associate Professor, Department of Microbiology, Lokmanya Tilak Municipal Medical College and General Hospital, Sion, Mumbai. ${ }_{2}^{2}$ Postgraduate Resident, Department of Microbiology, Lokmanya Tilak Municipal Medical College and General Hospital, Sion, Mumbai. 3 Professor and HOD, Department of Microbiology, Lokmanya Tilak Municipal Medical College and General Hospital, Sion, Mumbai.

\section{ABSTRACT}

\section{BACKGROUND}

Malaria is a major global health problem. An accurate and rapid clinical and laboratory diagnosis of malaria becomes essential to decrease the morbidity and mortality caused by it. The present study was conducted to study the clinical characteristics and haematological and biochemistry parameters in malaria patients.

\section{METHODS}

The prospective study included 200 patients clinically suspected of malaria and carried out at a tertiary care hospital. A thorough history and clinical details of patients were taken. Blood $(2 \mathrm{~mL})$ was collected in EDTA bulb from each patient and peripheral smears prepared and stained with Giemsa stain. Haematological investigations, LFT, and RFT of the patients were noted from the patient's records. Data was statistically analysed.

\section{RESULTS}

Malarial parasites were detected in 132 of 200 (66\%) patients in peripheral smears. Of these, 94 (71\%), 33 (25\%), and 5 (4\%) were $P$. vivax, $P$. falciparum, and mixed infections respectively. Maximum number of cases was in age group 11 to 30 years. Male-tofemale ratio was 4.7:1. Constitutional symptoms were seen in both peripheral smear positive and negative cases. CNS involvement was seen both in P. falciparum (24\%) and P. vivax infection (4\%), although significantly more in P. falciparum infections. Anaemia in P. falciparum (46\%) and thrombocytopenia in P. vivax malaria (39\%) was of statistical significance. Systemic manifestations and mortality were higher in P. falciparum (33\%) than P. vivax (4\%) infection.

\section{CONCLUSION}

Clinical signs and symptoms alone cannot be used to diagnose malaria. It has to be confirmed by laboratory diagnosis. Systemic complications and mortality is caused by both $P$. vivax and $P$. falciparum, but significantly more by P. falciparum. Haematological abnormalities like anaemia and thrombocytopenia should increase the possibility of malaria. Periodic analysis of the clinical manifestations with haematological and biochemistry parameters can reveal the changing behavioral patterns of the plasmodium species so that appropriate treatment and preventive measures can be taken.

\section{KEYWORDS}

Malaria, P. falciparum, P. vivax, Plasmodium Species.

HOW TO CITE THIS ARTICLE: Kumar CA, Gaikwad D, Baveja S. Clinical and haematological profile in malaria at a tertiary care hospital. J. Evolution Med. Dent. Sci. 2016;5(66):4692-4695, DOI: 10.14260/jemds/2016/1069

\section{INTRODUCTION}

Malaria is a protozoan disease caused by infections with the parasite of the genus Plasmodium and transmitted to man by certain species of infected female anopheles mosquito. Today, with the increased frequency of human migration, the disease has become a global health problem. Malaria has plagued mankind since ancient times and is still a significant threat to half of the world's population - 3.3 billion people living in 109 countries are at risk of contracting the disease. Estimates suggest that malaria afflicts between 350 and 500 million people every year. ${ }^{1}$ India accounts for approximately two thirds of the confirmed cases reported in South East Asia Region. In 2008, 1.5 million confirmed cases were reported.

Financial or Other, Competing Interest: None

Submission 26-07-2016, Peer Review 07-08-2016,

Acceptance 09-08-2016, Published 16-08-2016.

Corresponding Author:

Dr. Chaya Ashok Kumar,

Lokmanya Tilak Municipal Medical

College \& General Hospital, Sion,

Mumbai-400022,

Maharashtra, India

E-mail: k.chaya@gmail.com

DOI: $10.14260 /$ jemds/2016/1069
The number has fallen from more than 2 million confirmed cases in 2001 to 1.5 million cases in 2008. About half of the cases confirmed are due to P. falciparum. Five states account for $60 \%$ cases: Orissa, Chhattisgarh, Madhya Pradesh, Jharkhand, and West Bengal. Other highly endemic states include Arunachal Pradesh, Assam, Meghalaya, and Tripura. ${ }^{2}$

\section{OBJECTIVES}

To study the clinical characteristics and haematological and biochemistry parameters in malaria patients diagnosed microscopically.

\section{MATERIAL AND METHODS}

The present study was carried out at a tertiary care hospital over a period of one and a half years after taking approval from the institutional ethics committee. The sample size was calculated according to the sensitivity and specificity of Giemsa staining and rapid diagnostic tests. ${ }^{3,4}$

Two hundred blood samples were obtained from patients of all ages with clinical suspicion of malaria. Patients who came for follow-up visits of an earlier episode of malaria or within 4 weeks post treatment were excluded from the study. 
A through history and clinical details of the patients were noted. Blood (2 $\mathrm{mL})$ was collected from each patient in an EDTA bulb and peripheral smear prepared and stained with Giemsa stain. A diagnosis of malaria was made and species identification done on noting of the morphology of the stages of parasite. The details of haemoglobin, total leucocyte and differential counts, liver and renal function tests were taken from the patient's record and noted.

Data were analysed in SPSS. Proportions were compared using the chi-square test.

\section{RESULTS}

A total of 200 patients, 163 males and 37 females were enrolled in the study. Twenty patients were admitted to the intensive care unit and the rest to the general wards.

Of the 200 samples processed in the laboratory, $132 \mathrm{had}$ positive blood films. Ninety four of the 132 (71\%) infecting species were identified as $P$. vivax, 33 (25\%) as $P$. falciparum, and $5(3.8 \%)$ as mixed infections.

Maximum number of cases was seen in the age group between 11-30 years. Males were affected more than females with male-to-female ratio of 4.73:1 (Table 1).

Rash, bleeding manifestations, cough, breathlessness, jaundice, oliguria, altered sensorium, and convulsions were included in the symptoms suggestive of complications. Fever was seen in $100 \%$ cases including negative patients. Constitutional symptoms were seen in both Plasmodium species and negative patients with no statistical significant difference. Symptoms suggestive of complications were seen more in cases with P. falciparum and the difference was statistically significant (Table 2).

Signs like pyrexia, tachycardia, hypotension, tachypnea, and bleeding diathesis were more common in malaria positive cases, but the difference was not statistically significant. Pallor was more common in P. falciparum and mixed cases and the finding was statistically significant. Icterus was more common in cases with $P$. falciparum with statistically significant difference (Table 3).

CNS manifestations were found to be higher in $P$. falciparum cases and the difference was statistically significant. All types of systemic manifestations were observed to be more in P. falciparum when compared to P. vivax and negative cases, but the findings were not statistically significant except for CNS complications (Table 4).

Anaemia was more common in cases of $P$. falciparum and mixed infections. Thrombocytopenia was more common in $P$. vivax cases and mixed infections. Both findings were statistically significant. Leucopenia was more common in $P$. vivax cases while hypoglycaemia was more common in $P$. falciparum cases. Deranged RFTs were higher in P. falciparum and mixed cases, but the findings were not statistically significant. Deranged LFTs were higher in negative and $P$. falciparum cases, but the findings were also not statistically significant (Table 5).

Mortality was observed to be the maximum in $P$. falciparum cases; 11 of 33 cases (33.33\%) and this was statistically significant. Of the 94 cases of P. vivax $4(4.25 \%)$ expired. No deaths were observed in the 5 cases of mixed cases. Of the 68 non-malaria cases as per peripheral smear positivity, $1(1.47 \%)$ patient expired.

\begin{tabular}{|c|c|c|c|}
\hline Age (Years) & Female & Male & Total \\
\hline $0-10$ & 2 & 3 & 5 \\
\hline $11-20$ & 5 & 31 & 36 \\
\hline $21-30$ & 2 & 33 & 35 \\
\hline $31-40$ & 6 & 9 & 15 \\
\hline $41-50$ & 6 & 15 & 21 \\
\hline $51-60$ & 0 & 15 & 15 \\
\hline$>60$ & 2 & 3 & 5 \\
\hline Total & $\mathbf{2 3}$ & $\mathbf{1 0 9}$ & $\mathbf{1 3 2}$ \\
\hline \\
Table 1: Age and Sex Distribution in \\
\hline
\end{tabular}

\begin{tabular}{|c|c|c|c|c|c|c|c|}
\hline Symptoms & $\begin{array}{c}\text { P. falciparum } \\
(n=33) \\
(\%)\end{array}$ & $\begin{array}{c}\text { P. vivax } \\
(n=94) \\
(\%)\end{array}$ & $\begin{array}{c}\text { Mixed } \\
(n=5) \\
(\%)\end{array}$ & $\begin{array}{c}\text { Negative } \\
(n=68) \\
(\%)\end{array}$ & $\begin{array}{c}\text { Total } \\
(n=200)(\%)\end{array}$ & $\begin{array}{l}\text { Chi } \\
\text { square }\end{array}$ & $\begin{array}{c}P \\
\text { value }\end{array}$ \\
\hline Fever & $33(100.00)$ & $94(100.00)$ & $5(100.00)$ & $68(100.00)$ & $200(100.00)$ & NA & NA \\
\hline Chills and rigors & $28(84.84)$ & $86(91.48)$ & $5(100.00)$ & $67(98.52)$ & $186(93.00)$ & 7.268 & 0.064 \\
\hline Nausea and Vomiting & $17(51.51)$ & $46(48.93)$ & $3(60.00)$ & $34(50.00)$ & $100(50.00)$ & 0.273 & 0.965 \\
\hline Headache & $12(36.36)$ & $36(38.29)$ & $2(40.00)$ & $29(42.64)$ & $79(39.50)$ & 0.476 & 0.924 \\
\hline Body ache & $6(18.18)$ & $32(34.04)$ & $1(20.00)$ & $35(51.47)$ & $74(37.00)$ & 14.55 & 0.024 \\
\hline $\begin{array}{c}\text { Symptoms suggestive of } \\
\text { complication* }\end{array}$ & *22 (66.66) & $40(42.55)$ & $2(40.00)$ & $22(32.35)$ & $114(57.00)$ & $10.712^{* *}$ & $0.01^{* *}$ \\
\hline
\end{tabular}

Table 2: Clinical Symptoms in Cases of Malaria and its Correlation with Plasmodium Species

\begin{tabular}{|c|c|c|c|c|c|c|c|}
\hline $\begin{array}{c}\text { Clinical } \\
\text { Signs }\end{array}$ & $\begin{array}{c}\text { P. falciparum } \\
(\mathrm{n}=33) \\
(\%)\end{array}$ & $\begin{array}{c}\text { P. vivax } \\
(n=94) \\
(\%)\end{array}$ & $\begin{array}{c}\text { Mixed } \\
(n=5) \\
(\%)\end{array}$ & $\begin{array}{c}\text { Negative } \\
(n=68) \\
(\%)\end{array}$ & $\begin{array}{c}\text { Total } \\
(n=200)(\%)\end{array}$ & $\begin{array}{c}\text { Chi } \\
\text { square }\end{array}$ & $\begin{array}{c}P \\
\text { value }\end{array}$ \\
\hline Pyrexia & $9(27.27)$ & $20(21.27)$ & $1(20.00)$ & $6(8.82)$ & $26(13.00)$ & 7.673 & 0.053 \\
\hline Tachycardia & $9(27.27)$ & $12(12.76)$ & $1(20.00)$ & $9(13.23)$ & $31(15.50)$ & 4.372 & 0.024 \\
\hline Hypotension & $3(9.09)$ & $7(7.44)$ & $0(00.00)$ & $2(2.94)$ & $12(6.00)$ & NA & NA \\
\hline Tachypnea & $7(21.21)$ & $3(3.19)$ & $0(00.00)$ & $1(1.47)$ & $11(5.50)$ & NA & NA \\
\hline Pallor & $* 14(42.42)$ & $27(28.72)$ & $* 4(80.00)$ & $15(22.07)$ & $60(30.00)$ & $10.493^{*}$ & $0.015^{*}$ \\
\hline Icterus & $* 17(51.51)$ & $17(18.08)$ & $1(20.00)$ & $13(19.11)$ & $48(24.00)$ & $16.43^{* *}$ & $0.001^{* *}$ \\
\hline Bleeding diathesis & $5(15.15)$ & $9(9.57)$ & $0(00.00)$ & $3(4.11)$ & $17(8.50)$ & 3.943 & 0.268 \\
\hline
\end{tabular}




\begin{tabular}{|c|c|c|c|c|c|c|c|}
\hline $\begin{array}{c}\text { Systemic } \\
\text { Manifestations }\end{array}$ & $\begin{array}{c}\text { P. falciparum } \\
(\mathrm{n}=33) \\
(\%)\end{array}$ & $\begin{array}{c}\text { P. vivax } \\
(n=94) \\
(\%) \\
\end{array}$ & $\begin{array}{c}\text { Mixed } \\
(n=5) \\
(\%) \\
\end{array}$ & $\begin{array}{c}\text { Negative } \\
(\mathrm{n}=68) \\
(\%)\end{array}$ & $\begin{array}{c}\text { Total } \\
(n=200) \\
(\%)\end{array}$ & $\begin{array}{l}\text { Chi } \\
\text { square }\end{array}$ & $\begin{array}{c}P \\
\text { value }\end{array}$ \\
\hline Respiratory System (RS) & $8(24.24)$ & $15(15.95)$ & $1(20.00)$ & 8 (11.76) & $32(16.00)$ & 2.635 & 0.451 \\
\hline $\begin{array}{c}\text { Cardiovascular System } \\
\text { (CVS) }\end{array}$ & $3(9.09)$ & $3(3.19)$ & $0(00.00)$ & $0(00.00)$ & $6(3.00)$ & NA & NA \\
\hline $\begin{array}{c}\text { Gastrointestinal Tract } \\
\text { (GIT) }\end{array}$ & $5(15.15)$ & $9(9.57)$ & $1(20.00)$ & $3(4.41)$ & $18(9.00)$ & 4.049 & 0.256 \\
\hline Spleen & $9(27.27)$ & $20(21.27)$ & $0(00.00)$ & $10(14.70)$ & $39(19.5)$ & 3.666 & 0.300 \\
\hline Liver & $9(27.27)$ & $19(20.21)$ & $1(20.00)$ & $10(14.70)$ & $39(19.5)$ & 2.297 & 0.513 \\
\hline $\begin{array}{c}\text { Central Nervous System } \\
\text { (CNS) }\end{array}$ & *8 (24.24) & $4(4.2)$ & $0(00.00)$ & $7(10.29)$ & $19(9.50)$ & $11.924^{*}$ & $0.008^{*}$ \\
\hline
\end{tabular}

\begin{tabular}{|c|c|c|c|c|c|c|c|}
\hline $\begin{array}{l}\text { Haematological \& Biochemistry } \\
\text { Parameters }\end{array}$ & $\begin{array}{c}\text { P. falciparum } \\
(n=33) \\
(\%)\end{array}$ & $\begin{array}{c}\text { P. vivax } \\
(n=94) \\
(\%)\end{array}$ & $\begin{array}{c}\text { Mixed } \\
(n=5) \\
(\%)\end{array}$ & $\begin{array}{c}\text { Negative } \\
(n=68) \\
(\%)\end{array}$ & $\begin{array}{c}\text { Total } \\
(n=200) \\
(\%)\end{array}$ & $\begin{array}{l}\text { Chi } \\
\text { square }\end{array}$ & $\begin{array}{c}P \\
\text { value }\end{array}$ \\
\hline Anaemia $(\mathrm{Hb}<10$ gm \%) & $\begin{array}{c}* 15(\mathrm{n}=33) \\
(45.45)\end{array}$ & $\begin{array}{c}25(n=94) \\
(26.59)\end{array}$ & $\begin{array}{l}* 4(n=5) \\
(80.00)\end{array}$ & $\begin{array}{c}22(\mathrm{n}=68) \\
(32.35)\end{array}$ & $\begin{array}{c}66(n=200) \\
(33.00)\end{array}$ & $9.067^{* *}$ & $0.028^{* *}$ \\
\hline $\begin{array}{l}\text { Thrombocytopenia(Platelet count } \\
<1,50,000 \text { cumm) }\end{array}$ & $\begin{array}{l}9(n=33) \\
(27.27)\end{array}$ & $\begin{array}{c}* 37(n=94) \\
(39.36)\end{array}$ & $\begin{array}{l}* 5(n=5) \\
(100.00)\end{array}$ & $\begin{array}{c}17(\mathrm{n}=68) \\
(25.00)\end{array}$ & $\begin{array}{c}68(n=200) \\
(34.00)\end{array}$ & $14.030^{* *}$ & $0.003^{* *}$ \\
\hline Leucopenia(TLC $<4000$ cumm) & & $\begin{array}{r}19(\mathrm{n}= \\
(20 .\end{array}$ & $\begin{array}{l}1(n=5) \\
(20.00)\end{array}$ & $\begin{array}{c}13(\mathrm{n}=68) \\
(19.11)\end{array}$ & $\begin{array}{c}37(\mathrm{n}=200) \\
(18.50)\end{array}$ & 1.098 & 0.778 \\
\hline Hypoglycaemia & $\begin{array}{c}5(\mathrm{n}=33) \\
(15.15)\end{array}$ & $\begin{array}{c}9(\mathrm{n}=94) \\
(9.57)\end{array}$ & $\begin{array}{l}0(\mathrm{n}=5) \\
(0.00)\end{array}$ & $\begin{array}{c}8(n=68) \\
(11.76)\end{array}$ & $\begin{array}{c}22(\mathrm{n}=200) \\
(11.00)\end{array}$ & 1.4 & 0.697 \\
\hline $\begin{array}{c}\text { Deranged Liver Function Tests } \\
\text { (LFT) }\end{array}$ & $\begin{array}{c}10(\mathrm{n}=23) \\
(43.47)\end{array}$ & $\begin{array}{c}14(\mathrm{n}=60) \\
(23.33)\end{array}$ & $\begin{array}{l}2(n=5) \\
(40.00)\end{array}$ & $\begin{array}{c}25(\mathrm{n}=55) \\
(45.45)\end{array}$ & $\begin{array}{c}51(\mathrm{n}=200) \\
(35.66)\end{array}$ & 6.927 & 0.074 \\
\hline $\begin{array}{c}\text { Deranged Kidney Function Tests } \\
\text { (RFT) }\end{array}$ & $\begin{array}{c}13(\mathrm{n}=27) \\
(48.14)\end{array}$ & $\begin{array}{c}25(n=76) \\
(32.89)\end{array}$ & $\begin{array}{l}3(n=5) \\
(60.00)\end{array}$ & $\begin{array}{c}15(\mathrm{n}=57) \\
(26.31)\end{array}$ & $\begin{array}{c}56(n=200) \\
(33.93)\end{array}$ & 5.460 & 0.141 \\
\hline
\end{tabular}

\section{DISCUSSION}

Of the 200 samples processed in the laboratory, 132 had positive blood films. Ninety four of the 132 infecting species were identified as $P$. vivax, 33 as $P$. falciparum, and 5 as mixed infections. Maximum numbers of cases were seen in the age group of 11-30 years. Males were affected more than females. Several authors have reported similar age and sex distribution.5,6,7,8,9 Although, the study shows preponderance of males. Sex is not a direct factor in malaria, but may influence rates through occupation, the type of clothing used, or relative mobility. 10

Symptoms like fever, headache, body ache, nausea, and vomiting were seen in both groups; one positive for and other negative for Plasmodium species on peripheral blood smear examination. There was no statistically significant difference seen. Signs like pyrexia, tachycardia, hypotension, tachypnea, and bleeding diathesis were more common in malaria positive cases, but the difference was not statistically significant. This emphasizes the need for a laboratory-based diagnosis rather than a complete dependence on clinical diagnosis. It would improve patient care, ensure accurate treatment of cases, and reduce morbidity and mortality of patients.

Symptoms suggestive of complications like rash, bleeding manifestations, cough, breathlessness, jaundice, oliguria, altered sensorium, and convulsions along with signs like pallor and icterus were significantly higher in P. falciparum cases. Systemic manifestations were also higher in $P$. falciparum cases. These findings are similar to those mentioned in literature.

Plasmodium vivax has a reputation as a benign infection, when compared with severe manifestations frequently observed with untreated P. falciparum. However, severe and fatal infections can occur with $P$. vivax. In the present study, $P$. vivax is seen to cause various systemic complications and the mortality observed with this species was $4.25 \%$. More recently, $P$. vivax has shown to cause severe anaemia, respiratory distress, malnutrition, and possibly coma. ${ }^{11}$

CNS complications and mortality were significantly higher in $P$. falciparum when compared to $P$. vivax. In the present study, CNS involvement was seen in 8 out of 33 P. falciparum cases $(24.24 \%)$ and 4 out of 94 cases (4.2\%) of vivax malaria. Cerebral malaria remains the single most important cause of mortality in falciparum malaria. Bag et al have reported cerebral involvement in 70\% patients of complicated malaria. There are infrequent reports of cerebral malaria associated with $P$. vivax. CNS involvement with $P$. vivax has been reported in only 45 cases in English literature since 1920; about half of these cases have occurred in children. ${ }^{12}$ Thapa et al have reported 2 cases of $P$. vivax malaria complicated with seizures and symptoms of diffuse meningoencephalitis from Kolkata. ${ }^{12}$

In the present study, anaemia was significantly higher in $P$. falciparum cases. Hypoglycaemia, deranged LFTs and RFTs were also seen more with $P$. falciparum malaria, but not significantly so. These findings are traditionally seen more commonly with $P$. falciparum and mentioned in literature.

In the present study, thrombocytopenia and leucopenia were more common in $P$. vivax cases. Thrombocytopenia was significantly higher in $P$. vivax than $P$. falciparum cases.

Song et al have studied the clinical features of $P$. vivax malaria in Korea. Thrombocytopenia was a prominent finding in $75 \%$ of the cases at diagnosis, which resolved during therpy. ${ }^{13}$ Memon et al when studying thrombocytopenia in hospitalised patients found $(70 \%)$ patients had thrombocytopenia. $93 \%$ patients with thrombocytopenia 
were $P$. falciparum positive and only $7 \%$ patients had vivax malaria. ${ }^{14}$

Various other studies have shown that thrombocytopenia is equally or even more common in $P$. vivax malaria contrary to the belief that abnormal haematological parameters is observed in $P$. falciparum malaria.15,16,17 More cases of thrombocytopenia in vivax malaria infection may attribute to possible development of a new genotype of $P$. vivax.18 Haematological abnormalities like anaemia and thrombocytopenia should increase the possibility of malaria especially when microscopy is negative taking into consideration the life cycle of the parasite.

\section{CONCLUSION}

Both $P$. vivax and $P$. falciparum can give rise to various systemic complications including cerebral malaria. Mortality is also caused by both the species, although $P$. falciparum continues to cause more complications and mortality compared to $P$ vivax. Haematological abnormalities like anaemia and thrombocytopenia should increase the possibility of malaria. Periodic studies and analysis of the clinical manifestations with haematological and biochemistry parameters will reveal the changing behavioral patterns of the plasmodium species so that appropriate treatment and preventive measures can be taken.

\section{REFERENCES}

1. World Health Organisation. World malaria report 2008.

2. World Health Organisation. World malaria report 2009.

3. Beam CA. Strategies for improving power in diagnostic radiology research. AJR Am J Roentgenol 1992;159(3):631-7.

4. Casagrande JT, Pike MC. An improved approximate formula for calculating sample sizes for comparing two binomial distributions. Biometrics 1978;34(3):483-6.

5. Gupta S, Gunter JT, Novak RJ, et al. Patterns of Plasmodium vivax and Plasmodium falciparum malaria underscore importance of data collection from private healthcare facilities in India. Malaria Journal 2009;8:227.
6. Shukla MM, Singh N, Singh MP, et al. Cerebral malaria in Jabalpur, India. Indian J Malariol 1995;32(2):70-5.

7. Mishra SK, Mohanty S. Clinical presentations of severe and complicated malaria in India. Indian Academy of Clinical Medicine 2001;2(3):125-7.

8. Singh R, Kaur M, Arora D. A prospective study of hepatic involvement in Plasmodium falciparum malaria. Journal of Clinical and Diagnostic Research 2010;4(2):2190-7.

9. Muddaiah M, Prakash PS. A study of clinical profile of malaria in a tertiary referral centre in South Canara. J Vector Borne Dis 2006;43(1):29-33.

10. Ang E, Alora BD. Clinical profile of malaria at UST Hospital: a review of 55 cases. Phil J Microbiol Infect Dis 1980;9(2):135-44.

11. Price RN, Tjitra E, Guerra CA, et al. Vivax malaria: neglected and not benign. Am J Trop Med Hyg 2007;77(Suppl 6): 79-87.

12. Thapa R, Patra V, Kundu R. Plasmodium vivax cerebral malaria case report. Indian Paediatrics 2007;44:433-4

13. Song $\mathrm{HH}$, SO $\mathrm{O}$, Kim $\mathrm{SH}$, et al. Clinical features of Plasmodium vivax malaria. The Korean Journal of Internal Medicine 2003;18(4):220-4.

14. Memon AR, Afsar S. Thrombocytopenia in hospitalised malaria patients. Pak J Med Sci 2006;22(2):141-3.

15. Aggarwal A, Rath S, Shashiraj. Plasmodium vivax malaria presenting with severe thrombocytopenia. J Trop Paediatr 2005;51(2):120-1.

16. Anstey NM, Currie BJ, Dyer ME. Profound thrombocytopenia due to Plasmodium vivax malaria. Aust N Z J Med 1992;22(2):169-70.

17. Harish R, Gupta S. Plasmodium vivax malaria presenting with severe thrombocytopenia, cerebral complications and hydrocephalus. Indian J Paediatr 2009;76(5):551-2.

18. Metanat M, Sharifi-Mood B. Malaria vivax and severe thrombocytopenia in Iran. Iran J Parasitol 2010;5(3):6970 . 